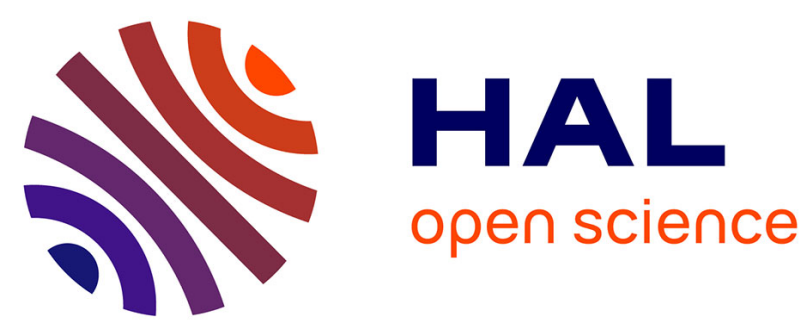

\title{
Depression, treatable cardiovascular risk factors and incident cardiac events in the Gazel cohort
}

Nadine Hamieh, Pierre Meneton, Emmanuel Wiernik, Frédéric Limosin, Marie Gay Zins, Marcel Goldberg, Maria Melchior, Cédric Lemogne

\section{- To cite this version:}

Nadine Hamieh, Pierre Meneton, Emmanuel Wiernik, Frédéric Limosin, Marie Gay Zins, et al.. Depression, treatable cardiovascular risk factors and incident cardiac events in the Gazel cohort. International Journal of Cardiology, 2019, 284, pp.90-95. 10.1016/j.ijcard.2018.10.013 hal-01944262

\section{HAL Id: hal-01944262 \\ https://hal.sorbonne-universite.fr/hal-01944262}

Submitted on 4 Dec 2018

HAL is a multi-disciplinary open access archive for the deposit and dissemination of scientific research documents, whether they are published or not. The documents may come from teaching and research institutions in France or abroad, or from public or private research centers.
L'archive ouverte pluridisciplinaire HAL, est destinée au dépôt et à la diffusion de documents scientifiques de niveau recherche, publiés ou non, émanant des établissements d'enseignement et de recherche français ou étrangers, des laboratoires publics ou privés. 
Depression, treatable cardiovascular risk factors and incident cardiac events in the Gazel cohort

Nadine M. Hamieh ${ }^{1,}{ }^{*}{ }^{\dagger}$, Ph.D. student, Pierre Meneton ${ }^{2,} \dagger$, Ph.D., Emmanuel Wiernik ${ }^{3, \dagger}$, Ph.D., Frederic Limosin ${ }^{4}{ }^{\dagger}$, M.D., Ph.D., Marie Zins ${ }^{5, \dagger}$, M.D., Ph.D., Marcel Goldberg ${ }^{5, \dagger}$, M.D., Ph.D., Maria Melchior ${ }^{1, \dagger}$, Sc.D., Cedric Lemogne ${ }^{4, \dagger}$, M.D., Ph.D.

${ }^{1}$ Department of Social Epidemiology, INSERM UMR_S 1136, Pierre Louis Institute of Epidemiology and Public Health, Paris, France; Sorbonne Universities, UPMC University of Paris 06, Paris, France

${ }^{2}$ INSERM U1142 LIMICS, UMRS 1142, Sorbonne Universities, UPMC University of Paris 06, University of Paris 13, Paris, France

${ }^{3}$ INSERM, Population-based Epidemiological Cohorts Unit, UMS 011, Villejuif, France

${ }^{4}$ Assistance Publique-Hopitaux de Paris (APHP), European Georges Pompidou Hospital, Department of Psychiatry, Paris, France; INSERM UMR 894, Psychiatry and Neuroscience Center, Paris, France; Paris Descartes University, Paris, France

${ }^{5}$ Faculty of Medicine, Paris Descartes University, Paris, France; INSERM, Population-based Epidemiological Cohorts Unit, UMS 011, Villejuif, France

${ }^{\dagger}$ The author takes responsibility for all aspects of the reliability and freedom from bias of the data presented and their discussed interpretation

\section{*Corresponding author:}

Nadine Hamieh, PhD student

Pierre Louis Institute for Epidemiology and Public Health (IPLESP/ INSERM UMR_S 1136)

Department of Social Epidemiology (ERES)

Faculty of Medicine, Saint-Antoine

27 rue de Chaligny

75012 Paris, France

Email: nadine.hamieh@iplesp.upmc.fr

Tel: +33(0) 666883803 


\section{ACKNOWLEDGMENTS}

Nadine Hamieh is supported by Philippe Jabre Association to conduct this project which is part of her PhD thesis. Cedric Lemogne was supported by a grant from IReSP (LEMOGNE AAP16_PREV-13).The Gazel cohort is supported by 'Agence nationale de la recherche', 'Institut National de la Santé et de la Recherche Médicale', 'Agence française de sécurité sanitaire de l'environnement et du travail' and 'Caisse d'Assurance Maladie des Industries Electriques et Gazières'.

\section{DECLARATION OF INTEREST}

Cedric Lemogne declares grants, personal fees and non-financial support from Lundbeck, personal fees from Servier, non-financial support from Otsuka Pharmaceuticals, and personal fees from Janssen-Cilag, outside the submitted work. Frederic Limosin has received speaker and consulting fees from AstraZeneca, Janssen, Lundbeck, Otsuka Pharmaceuticals, Roche and Servier. The other authors declare no potential conflicts of interest.

Keywords: depression; cardiac events; hypertension; diabetes; dyslipidemia; epidemiology 


\section{ABSTRACT}

Background: Depression is an important risk factor of cardiovascular disease (CVD), a leading cause of death worldwide. One of the reasons underlying this association may be that depression modifies the association between treatable cardiovascular risk factors and cardiac events (angina pectoris or myocardial infarction). We tested this hypothesis in a cohort study of middle-aged men and women in France followed for 20 years.

Methods: 10,541 Gazel working men and women free of cardiovascular disease at baseline (1993) were followed-up over 20 years for validated incident cardiac events. Depression was measured at baseline and every three years with the Center for Epidemiological StudiesDepression (CES-D). We used time-dependent Cox regression models to calculate hazard ratios (HR) of cardiac events associated with depression, main treatable cardiovascular risk factors (hypertension, diabetes, and dyslipidemia), and their interactions, adjusting for demographic, lifestyle and clinical characteristics.

Results: Over 20 years of follow-up, 592 incident cases of cardiac events were identified. Depression was significantly associated with incident cardiac events (HR 1.55, $P=0.002$ ), as was hypertension (HR 1.49, $P=0.02$ ), diabetes (HR 2.54, $P=0.001$ ), and dyslipidemia (HR 1.55, $P=0.003$ ). No statistically significant interactions were observed between depression and hypertension, diabetes or dyslipidemia in relation to incident cardiac events (all $P \geq 0.16$ ).

Conclusions: The association between depression and cardiac events is unlikely to be explained by a heightened impact of hypertension, diabetes or dyslipidemia. 


\section{INTRODUCTION}

Cardiovascular diseases (CVD) and depression are respectively leading causes of death [1] and disability [2] worldwide according to World Health Organization. CVD is estimated to contribute to $31 \%$ of total mortality, that is approximately 17.7 million deaths in 2015 [1]: which is an increase by 0.7 million from 2013-2015 [3]. Currently, depression affects more than 300 million individuals: this number increased by 18\% from 2005-2015 [2]. In France, CVD is the second leading cause of death with approximately 140,000 deaths per year [4] (27\% of all deaths in 2011) [5], while the prevalence of depression is estimated at 5 to $12 \%$ in the general population [6].

CVD and depression are highly comorbid, and this association is probably bidirectional. Approximately 30-45\% of patients with CVD suffer from elevated levels of depressive symptoms [7] and while depression predicts CVD onset (i.e. depressed individuals are 1.5 times higher to develop CVD compared to non-depressed [8]), the opposite can also be the case. One of the potential explanations is that depression co-occurs with traditional cardiovascular risk factors [9] such as obesity [10, 11], hypertension [12], diabetes [13, 14], hypercholesterolemia [15] and smoking [16-18].

Several large-scale prospective studies found that major depression, or subthreshold depressive symptoms, are independent risk factors of CVD [7, 19-23]. Additionally, a metaanalysis conducted on prospective cohort studies to assess the association between depression and the incidence of coronary heart disease (CHD) and myocardial infarction in 2014, adjusting for obesity, diabetes, cholesterol, hypertension, alcohol intake, smoking, physical activity, age and gender, found a relative risk (RR) for both CHD and myocardial infarction of 1.30 with a $95 \%$ confidence interval (CI) of 1.18-1.40 [24]. Two other meta-analyses showed that depressed individuals who were free of $\mathrm{CHD}$ at baseline were 1.5 times more likely to develop CHD as compared with non-depressed individuals, independent of CHD risk 
factors $[7,25]$. Thus, depression seems directly related to CVD, however the possibility that it acts as a moderator of other established risk factors has not been fully examined.

One limitation of previous studies is that most assumed that changes in cardiovascular risk factors over time do not vary with depression. In addition, some critical mechanisms potentially linking depression with CVD risk, such as access to treatment and adherence to medication, have rarely been taken into account. Since depression is a well-established risk factor of poor adherence to medication across a large variety of health conditions [26], including treatable cardiovascular risk factors (i.e. hypertension, diabetes, dyslipidemia) [19, 27-29], one may hypothesize that depression can heighten the risk of CVD associated with these preventable risk factors. In other words, depression could act as an effect modifier of traditional cardiovascular risk factors. Previous studies found indication of an interaction between depression and hypertension [30] as well as with diabetes (in women) [31], but were not consistent with each other and did not model depression as a time-dependent variable. Given that cardiovascular risk factors and depressive symptoms can vary over time, it is important to test for interactions between these different sources of risk in a longitudinal framework. The present study took advantage of the repeated assessment of depression and hypertension, diabetes and dyslipidemia in the Gazel cohort for 20 years of follow-up to examine whether depression modifies the prospective association between these treatable risk factors and incident cardiac events. We focused on hypertension, diabetes and dyslipidemia since they are known as cardiovascular risk factors with established pharmacologic treatment and because depression has been associated with poor adherence to these medications, hence we hypothesized that their association with incident cardiac events would increase in the presence of depressive symptoms.

\section{MATERIALS AND METHODS}




\subsection{Study population}

The Gazel cohort, a prospective study, was initiated in 1989 among 20,625 employees $(5,614$ women and 15,011 men aged 35-50 and 40-50 respectively) of Électricité de France-Gaz de France (EDF-GDF) $[32,33]$. These participants represented $46 \%$ of the EDF-GDF employees of this age range. Participants were followed-up yearly since 1989 through administrative databases (i.e. human resources databases) and postal self-administrated questionnaires. In the present analyses, we included participants who completed the Center for Epidemiologic Studies Depression Scale (CES-D) in $1993(\mathrm{n}=14,893)$. These 14,893 participants were significantly older, more likely to be physically inactive, had a higher occupational grade, were less likely to be female and to report diabetes, hypertension and dyslipidemia compared to those who did not complete the CES-D questionnaire. In this population, participants with a cardiac event before $1994 \quad(n=332)$, and missing data on our variables of interest (hypertension, diabetes, dyslipidemia, occupational grade, parental CHD history, obesity, smoking status and physical inactivity) before $1993(n=4,020)$ were excluded. Hence, our final population consisted of 10,541 participants who were followed-up for cardiac events from January 1, 1994-December 31, 2014. These individuals were significantly older, more likely to be non-smokers, non-obese, had a higher occupational grade, were less likely to be female and to report depression and dyslipidemia compared to non-participants with completed CES-D questionnaire (29.2\%).

The 'Commission Nationale Informatique et Liberté' and 'Institut National de la Santé et de la Recherche Médicale' ethics committee approved the study [33, 34] and all the participants provide written informed consent.

\subsection{Assessment of cardiac events}

Diagnosis of cardiac events was performed using two different sources over a 20 years follow-up period from January 1, 1994 to December 31, 2014. First, while participants were 
actively employed, cases of coronary heart disease were identified in the ad-hoc registry set up by the EDF-GDF medical department [34] and medically validated. Second, after participants retired, diagnoses were based on self-reported cardiac events that were systematically validated. Specifically, all participants were asked to report whether they had been diagnosed or hospitalized due to cardiovascular disease including angina pectoris or myocardial infarction in the 12 months preceding the yearly Gazel questionnaire. If a participant was alive, gave consent, and reported at least 1 cardiac event, he/she was contacted to transmit his/her medical records. All cardiac events were validated by two trained investigators.

\subsection{Assessment of cardiovascular risk factors of interest}

Information on hypertension, diabetes and dyslipidemia was collected annually from 19932013 from participants' self-reports on the following 2 questions: "In the list below, indicate the diseases that you have suffered from in the past 12 months?" and "Among the health problems that you have indicated, which ones are new (i.e. they have appeared in the last 12 months)?" These cardiovascular risk factors were considered separately but also in a cumulative manner, combining hypertension, diabetes and dyslipidemia over the entire follow-up and irrespective of the risk factor $(0,1,2$, and 3$)$.

\subsection{Assessment of depressive symptoms}

Information on depression has been assessed every three years since 1993 using the validated French version of the CES-D, a scale composed of 20 items of depressive symptoms [35]. The CES-D questionnaire has a high internal consistency coefficient of $0.8-0.9$ across community samples [36]. This screening test measures sadness, loss of interest, appetite, sleep, thinking, guilt, fatigue, agitation and suicidal thoughts during the previous week on a scale of 0 ( $<1$ day) to 3 ( 5 to 7 days). Women who scored $\geq 23$ and men who scored $\geq 17$ were considered to be clinically depressed [35]. In addition, depression was also assessed using a 
continuous variable taking the interquartile range (the difference between the $25^{\text {th }}$ and $75^{\text {th }}$ percentiles, i.e. 10 points) as a unit to deal with the small sample size of validated cardiac events when stratifying by depression status.

\subsection{Assessment of covariates}

Socio-demographics such as sex, age, occupational grade (low: manual and clerical; medium: technical; high: managerial positions) were collected from the EDF-GDF human resources records at baseline. Parental history of CHD (yes: either mother or father had CHD before the age of 60 , no), weight (continuous, $\mathrm{kg}$ ), height (continuous, meters), current smoking status (yes: current smokers; no: former and non-smokers) and physical inactivity (yes: none; no: occasionally or $\geq 1$ week) were collected annually from participants' self-administered questionnaires since 1993. Obesity was measured by body mass index, BMI (yes: BMI $\geq 30$; no: $\left.<30 \mathrm{~kg} / \mathrm{m}^{2}\right)$.

\subsection{Statistical analysis}

Each participant contributed person-time from the start date of our study, January 1, 1994 until the diagnosis of a cardiac event, death, the last follow-up questionnaire or December 31, 2014, whichever occurred first. We computed descriptive statistics such as ANOVA, Chisquare and Fisher's exact tests to compare participants' characteristics by incident cardiac events and depression status. Chi-square and Fisher's exact tests were computed for discrete variables whereas ANOVA test was computed for continuous ones.

Cox proportional hazard regressions were used to calculate the hazard ratios (HR) and 95\% confidence intervals (CI) of depression and cardiovascular risk factors of interest in relation to incident cardiac events. All models controlled for participants' age (in years) and sex. Multivariable models were additionally adjusted for obesity, smoking status, parental CHD, occupational grade and physical inactivity. Except for gender, age, parental CHD history and occupational grade, all characteristics were studied as time varying covariates 
using the programming statement method described by Powell and Bagnell [37]. To further explore whether depression could predict incident cardiac events independently of hypertension, diabetes and dyslipidemia, we conducted analyses in different subpopulations. Only the cumulative cardiovascular risk factors variable combining hypertension, diabetes and dyslipidemia over the entire follow-up in these subpopulations was not considered as time-dependent. The roughly parallel stratified Kaplan-Meier curves log (-log (survival)) versus $\log$ (time) transformation verified the proportionality of hazards.

To test the hypothesis that depression is an effect modifier of hypertension, diabetes and dyslipidemia regarding the risk of incident cardiac events, we tested for statistical interactions between depression and these risk factors, simultaneously including depression, each risk factor and their interaction in the statistical model. Additionally, we tested for the interaction of depression with sex in relation to incident cardiac events.

All p-values were two-sided with an $\alpha=0.05$. All statistical analyses were conducted using the SAS statistical software version 9.4 (SAS, Cary, NC) and its derived discovery software JMP version 12.

\section{RESULTS}

At baseline, $22.5 \%$ of the study population was depressed based on the CES-D score $(n=2,368$ participants) (Table 1). In a previous study based on the same study population [38], we found that being female $(P=0.02)$, a smoker $(P=0.03)$, a physically inactive person $(P<0.0001)$, and having a lower occupational grade $(P<0.0001)$, dyslipidemia $(P=0.004)$ and hypertension $(P=0.0003)$ were significantly associated with depression.

During the 20 years of follow-up, 592 individuals had a cardiac event (Table 1), yielding an incidence rate of 292 per 100,000 person-years [38]. These cardiac events included 485 CHD-related events (i.e. 160 angina pectoris and 315 myocardial infarction cases) and 117 other cardiac events (e.g. heart failure, cardiac arrhythmia). Overall, compared 
to participants with no incident cardiac event, those who had an incident cardiac event were more likely to be male, obese, to smoke, have a parental history of CHD and have diabetes or dyslipidemia. Among participants with an incident cardiac event, concurrent depression was not associated with any of the treatable cardiovascular risk factors whereas it was associated with hypertension $(P=0.0002)$ and dyslipidemia $(P=0.008)$ in those without incident cardiac events.

Depression was significantly associated with an incident cardiac event both adjusting for sex and age (HR 1.72, 95\% CI 1.37-2.17, $P<0.001)$ and in fully-adjusted models (HR 1.55, 95\% CI 1.17-2.05, $P=0.002$ ). Adjusting for sex, age and depression, individuals with hypertension, diabetes or dyslipidemia were at a higher risk of developing a cardiac event (Table 2). These associations remained statistically significant in the fully-adjusted model, but their magnitude was reduced. However, we observed no statistically significant interaction between depression and each of hypertension, diabetes and dyslipidemia (all $P$ $\geq 0.16$ ). When depression was modelled as a continuous variable, the findings were similar (Table 3) but with different magnitudes in terms of HRs and p-values for interaction.

Men were at a higher risk of having a cardiac event compared to women both in minimally-adjusted (HR 1.85, 95\% CI 1.35-2.53, $P=0.0001)$ and fully-adjusted models (HR $1.82,95 \%$ CI $1.24-2.68, P=0.002)$. No statistical interaction between depression and sex was observed: p-values for interaction were 0.79 in minimally-adjusted and 0.70 in fully-adjusted models (data not shown).

To further explore whether depression could predict incident cardiac events independently of hypertension, diabetes and dyslipidemia, despite the lack of significant interaction, we conducted analyses in different subpopulations according to the presence of these risk factors (Table 4). Overall, the fully-adjusted models yielded no compelling evidence that the risk of developing a cardiac event associated with depression increased in 
the presence of these risk factors. More specifically, the HR for individuals who had none of these risk factors over the entire follow-up was similar to the HR of those who had the three risk factors (1.34 versus 1.37).

\section{DISCUSSION}

The aim of this prospective study was to examine whether the association between treatable cardiovascular risk factors, namely hypertension, diabetes and dyslipidemia and incident cardiac events varied according to the presence of depression in a socioeconomically and geographically heterogeneous French population over a period of 20 years. In line with most previous studies $[8,9,20,21,25,30,31,33,39-43]$, depression was independently associated with incident cardiac events adjusting for differences in clinical and lifestyle patterns. The present investigation's unique contribution is the study of possible interactions between depression and these risk factors. Contrary to our a priori hypothesis, we found no evidence of modification of the effects of hypertension, diabetes or dyslipidemia by depression. Interactions between depression and these risk factors were not statistically significant and stratified analyses did not provide compelling indication that depression could predict incident cardiac events to a different extent among individuals with or without these risk factors over the entire follow-up. Thus, it is unlikely that non-adherence to medications related to these risk factors substantially explains the association between depression and incident cardiac events.

Although our results fall within the range of fully-adjusted HRs reported in the literature (i.e. 1.18 to 3.60 ) when confounders were measured at baseline, they are not consistent with negative studies, including one of our group also based on Gazel study data $[38,44]$. Interestingly, this discrepancy results from the fact that this previous study did not model depression as a time-dependent variable [33]. Here, modelling depression as well as 
hypertension, diabetes and dyslipidemia, was critical to test our hypothesis since these risk factors might appear during follow-up and depression level varies over time.

Our study is original in that we systematically searched for interactions between depression and each risk factor of interest regarding the incidence of cardiac events. Although the well-known association between depression and poor adherence to medications led us to hypothesize a significant interaction, this was not observed with hypertension, dyslipidemia or diabetes. Overall, there was no evidence for a consistent increase in the risk of cardiac events when depressed each time a risk factor was added. The lack association among individuals with no dyslipidemia could be explained by a lack of statistical power. Therefore, our results did not provide support for our initial hypothesis.

There are some notable strengths in these analyses. First, it is the first study to explore the interaction of depression with cardiovascular risk factors in relation to incident cardiac events, taking into account variation in these risk factors over the follow-up by using timedependent variables in Cox proportional hazard models. Second, ours is a prospective study with repeated measures with a long follow-up of 20 years with a very low attrition rate [32, 38]. Third, the Gazel cohort is a diverse population in terms of geography and socioeconomic position [32]. Fourth, the reliance upon a thoroughly validated diagnosis of cardiac events ensures the accuracy and reliability of our findings.

However, some limitations are present. Although this study was prospective, a randomized design was obviously impossible so that its observational nature prevents us from drawing causal inferences regarding the relationship between depression and incident cardiac events. Another limitation is that cardiovascular risk factors were self-reported. It is noteworthy that self-report accuracy may not be influenced by depressive status $[45,46]$ and that the present associations with cardiac events were consistent with the literature, thus providing evidence of external validity/generalizability. However, we cannot rule out that a 
non-differential misclassification occurred leading to some underestimation of the impact of these risk factors of on cardiac events.

Although our use of validated cardiac events is a strength, the total number of cases was relatively low they did not include fatal cases and false negatives may have occurred. In addition, the hypothesis of a mediation by lack of medication adherence was not tested directly, hence future studies should be conducted. A related limitation is that, since we focused on cardiovascular risk factors with an established pharmacologic treatment, our analysis did not search for an interaction with overweight or obesity, despite their strong association with depression $[47,48]$. Another limitation is that the CES-D does not measure major depression but rather depressive symptoms. However, it is noteworthy that even subthreshold depressive symptoms have been found to predict onset of cardiac events [33].

\section{CONCLUSIONS}

In conclusion, our finding showing that depression is associated with incident cardiac events independently of hypertension, diabetes or dyslipidemia has clinical implications. First, it can serve to convince physicians and public health decision makers that depression is a cardiovascular risk factor on its own. Indeed, the impact of depression may be comparable to that of hypertension and dyslipidemia in relation to incident cardiac events. Second, it suggests that non-behavioral pathways such as inflammation or autonomic dysregulation [49] should be further explored. 
[1] World Health Organization. Cardiovascular diseases (CVDs). World Health Organization; 2017, May 17.

[2] World Health Organization. Depression. 2018, March 22

[3] Murray CJL. Global, regional, and national age-sex specific all-cause and cause-specific mortality for 240 causes of death, 1990-2013: a systematic analysis for the Global Burden of Disease Study 2013. Lancet. 2015;385:117-71.

[4] Ministère des Solidarités e t de la Santé. Maladies cardiovasculaires. 2017, November 10.

[5] Tzoulaki I, Elliott P, Kontis V, Ezzati M. Worldwide Exposures to Cardiovascular Risk Factors and Associated Health Effects: Current Knowledge and Data Gaps. Circulation. 2016;133:2314-33.

[6] Chan Chee C, Gourier-Frery C, Guignard R, Beck F. [The current state of mental health surveillance in France]. Sante Publique. 2011;23 Suppl 6:S13-29.

[7] Celano CM, Huffman JC. Depression and cardiac disease: a review. Cardiol Rev. 2011;19:130-42.

[8] Wulsin LR, Singal BM. Do depressive symptoms increase the risk for the onset of coronary disease? A systematic quantitative review. Psychosom Med. 2003;65:201-10.

[9] Gaye B, Prugger C, Perier MC, Thomas F, Plichart M, Guibout C, et al. High level of depressive symptoms as a barrier to reach an ideal cardiovascular health. The Paris Prospective Study III. Sci Rep. 2016;6:18951.

[10] Phillips CM, Perry IJ. Depressive symptoms, anxiety and well-being among metabolic health obese subtypes. Psychoneuroendocrinology. 2015;62:47-53.

[11] LaGrotte C, Fernandez-Mendoza J, Calhoun SL, Liao D, Bixler EO, Vgontzas AN. The relative association of obstructive sleep apnea, obesity and excessive daytime sleepiness with incident depression: a longitudinal, population-based study. Int J Obes (Lond). 2016;40:1397404.

[12] Graham N, Smith DJ. Comorbidity of depression and anxiety disorders in patients with hypertension. J Hypertens. 2016;34:397-8.

[13] Mommersteeg PM, Herr R, Pouwer F, Holt RI, Loerbroks A. The association between diabetes and an episode of depressive symptoms in the 2002 World Health Survey: an analysis of 231,797 individuals from 47 countries. Diabet Med. 2013;30:e208-14.

[14] Ali S, Stone MA, Peters JL, Davies MJ, Khunti K. The prevalence of co-morbid depression in adults with Type 2 diabetes: a systematic review and meta-analysis. Diabet Med. 2006;23:1165-73.

[15] Almeida OP, Yeap BB, Hankey GJ, Golledge J, Flicker L. HDL cholesterol and the risk of depression over 5 years. Mol Psychiatry. 2014;19:637-8.

[16] Dierker LC, Avenevoli S, Stolar M, Merikangas KR. Smoking and depression: an examination of mechanisms of comorbidity. Am J Psychiatry. 2002;159:947-53.

[17] An R, Xiang X. Smoking, heavy drinking, and depression among U.S. middle-aged and older adults. Prev Med. 2015;81:295-302.

[18] Yun WJ, Shin MH, Kweon SS, Ryu SY, Rhee JA. Association of smoking status, cumulative smoking, duration of smoking cessation, age of starting smoking, and depression in Korean adults. BMC Public Health. 2012;12:724.

[19] Hare DL, Toukhsati SR, Johansson P, Jaarsma T. Depression and cardiovascular disease: a clinical review. Eur Heart J. 2014;35:1365-72.

[20] Van der Kooy K, van Hout H, Marwijk H, Marten H, Stehouwer C, Beekman A. Depression and the risk for cardiovascular diseases: systematic review and meta analysis. Int $\mathbf{J}$ Geriatr Psychiatry. 2007;22:613-26. 
[21] Case SM, Sawhney M, Stewart JC. Atypical depression and double depression predict new-onset cardiovascular disease in U.S. adults. Depress Anxiety. 2018;35:10-7.

[22] Ford DE, Mead LA, Chang PP, Cooper-Patrick L, Wang NY, Klag MJ. Depression is a risk factor for coronary artery disease in men: the precursors study. Arch Intern Med. 1998;158:1422-6.

[23] Lichtman JH, Froelicher ES, Blumenthal JA, Carney RM, Doering LV, Frasure-Smith N, et al. Depression as a risk factor for poor prognosis among patients with acute coronary syndrome: systematic review and recommendations: a scientific statement from the American Heart Association. Circulation. 2014;129:1350-69.

[24] Gan Y, Gong Y, Tong X, Sun H, Cong Y, Dong X, et al. Depression and the risk of coronary heart disease: a meta-analysis of prospective cohort studies. BMC Psychiatry. $2014 ; 14: 371$.

[25] Nicholson A, Kuper H, Hemingway H. Depression as an aetiologic and prognostic factor in coronary heart disease: a meta-analysis of 6362 events among 146538 participants in 54 observational studies. Eur Heart J. 2006;27:2763-74.

[26] Eze-Nliam CM, Thombs BD, Lima BB, Smith CG, Ziegelstein RC. The association of depression with adherence to antihypertensive medications: a systematic review. J Hypertens. 2010;28:1785-95.

[27] Wang PS, Bohn RL, Knight E, Glynn RJ, Mogun H, Avorn J. Noncompliance with antihypertensive medications: the impact of depressive symptoms and psychosocial factors. $\mathbf{J}$ Gen Intern Med. 2002;17:504-11.

[28] Stilley CS, Sereika S, Muldoon MF, Ryan CM, Dunbar-Jacob J. Psychological and cognitive function: predictors of adherence with cholesterol lowering treatment. Ann Behav Med. 2004;27:117-24.

[29] Ciechanowski PS, Katon WJ, Russo JE. Depression and diabetes: impact of depressive symptoms on adherence, function, and costs. Arch Intern Med. 2000;160:3278-85.

[30] Polanka BM, Berntson J, Vrany EA, Stewart JC. Are Cardiovascular Risk Factors Stronger Predictors of Incident Cardiovascular Disease in U.S. Adults With Versus Without a History of Clinical Depression? Ann Behav Med. 2018:1-10.

[31] Rutledge T, Linke SE, Johnson BD, Bittner V, Krantz DS, Cornell CE, et al. Relationships between cardiovascular disease risk factors and depressive symptoms as predictors of cardiovascular disease events in women. J Womens Health (Larchmt). 2012;21:133-9.

[32] Goldberg M, Leclerc A, Zins M. Cohort Profile Update: The GAZEL Cohort Study. Int J Epidemiol. 2015;44:77-g.

[33] Meneton P, Lemogne C, Herquelot E, Bonenfant S, Larson MG, Vasan RS, et al. A Global View of the Relationships between the Main Behavioural and Clinical Cardiovascular Risk Factors in the GAZEL Prospective Cohort. PLoS One. 2016;11:e0162386.

[34] Chevalier A, Zins M, Godard C, Morin J, Jourdain V, Francois F, et al. [ A registry of ischaemic cardiopathies among active workers at Electricite de France-Gaz de France. Program development and first results]. Rev Epidemiol Sante Publique. 2001;49:51-60.

[35] Fuhrer R, Rouillon F. La version française de l'échelle CES-D (Center for Epidemiologic Studies-Depression Scale). Description et traduction de l'échelle d'autoévaluation [The French version of the CES-D (Center for Epidemiologic Studies-Depression Scale)]. Psychiatrie \& Psychobiologie. 1989;4:163-6.

[36] Radloff LS. The CES-D Scale: A Self-Report Depression Scale for Research in the General Population. Applied Psychological Measurement 1977;1:385-401.

[37] Powell TM, Bagnell ME. Your "Survival" Guide to Using Time- Dependent Covariates. 2012 ed. SAS Global Forum 20122012. 
[38] Lemogne C, Meneton P, Wiernik E, Quesnot A, Consoli SM, Ducimetiere P, et al. When Blue-Collars Feel Blue: Depression and Low Occupational Grade as Synergistic Predictors of Incident Cardiac Events in Middle-Aged Working Individuals. Circ Cardiovasc Qual Outcomes. 2017;10.

[39] Nabi H, Kivimaki M, Suominen S, Koskenvuo M, Singh-Manoux A, Vahtera J. Does depression predict coronary heart disease and cerebrovascular disease equally well? The Health and Social Support Prospective Cohort Study. Int J Epidemiol. 2010;39:1016-24.

[40] Seldenrijk A, Vogelzangs N, Batelaan NM, Wieman I, van Schaik DJ, Penninx BJ. Depression, anxiety and 6-year risk of cardiovascular disease. J Psychosom Res. 2015;78:123-9.

[41] Almas A, Forsell Y, Iqbal R, Janszky I, Moller J. Severity of Depression, Anxious Distress and the Risk of Cardiovascular Disease in a Swedish Population-Based Cohort. PLoS One. 2015;10:e0140742.

[42] Wu Q, Kling JM. Depression and the Risk of Myocardial Infarction and Coronary Death: A Meta-Analysis of Prospective Cohort Studies. Medicine (Baltimore). 2016;95:e2815.

[43] Whang W, Kubzansky LD, Kawachi I, Rexrode KM, Kroenke CH, Glynn RJ, et al. Depression and risk of sudden cardiac death and coronary heart disease in women: results from the Nurses' Health Study. J Am Coll Cardiol. 2009;53:950-8.

[44] Vogt T, Pope C, Mullooly J, Hollis J. Mental health status as a predictor of morbidity and mortality: a 15-year follow-up of members of a health maintenance organization. Am $\mathbf{J}$ Public Health. 1994;84:227-31.

[45] Jeffery RW, Finch EA, Linde JA, Simon GE, Ludman EJ, Operskalski BH, et al. Does clinical depression affect the accuracy of self-reported height and weight in obese women? Obesity (Silver Spring). 2008;16:473-5.

[46] Barnes RD, White MA, Masheb RM, Grilo CM. Accuracy of self-reported weight and height and resulting body mass index among obese binge eaters in primary care: relationship with eating disorder and associated psychopathology. Prim Care Companion J Clin Psychiatry. 2010;12.

[47] Milaneschi Y, Simmons WK, van Rossum EFC, Penninx BW. Depression and obesity: evidence of shared biological mechanisms. Mol Psychiatry. 2018.

[48] Marx P, Antal P, Bolgar B, Bagdy G, Deakin B, Juhasz G. Comorbidities in the diseasome are more apparent than real: What Bayesian filtering reveals about the comorbidities of depression. PLoS Comput Biol. 2017;13:e1005487.

[49] Tawakol A, Ishai A, Takx RA, Figueroa AL, Ali A, Kaiser Y, et al. Relation between resting amygdalar activity and cardiovascular events: a longitudinal and cohort study. Lancet. 2017;389:834-45. 
Table 1. Baseline characteristics of 10,541 participants in Gazel cohort by depression and incident cardiac events

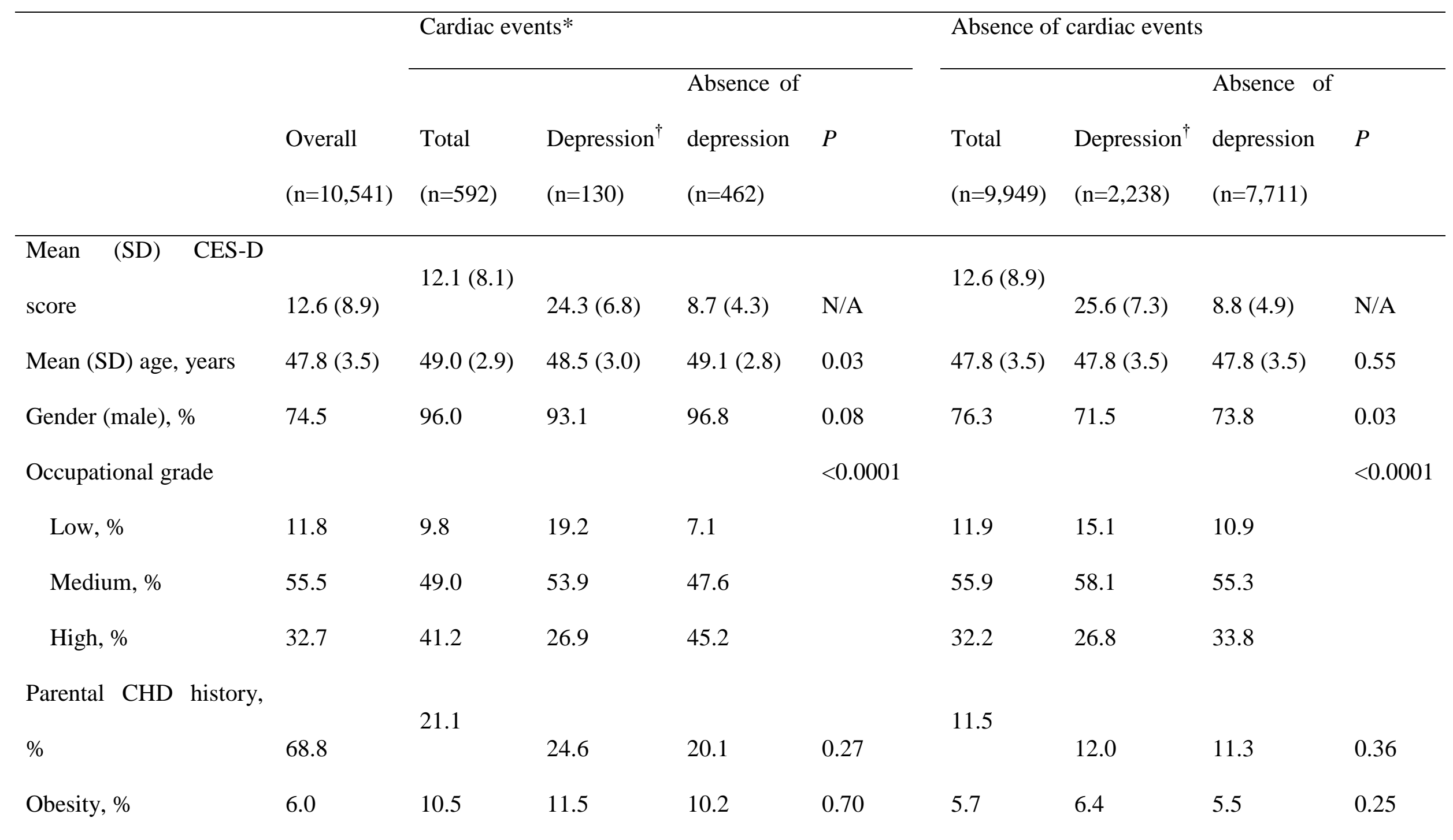




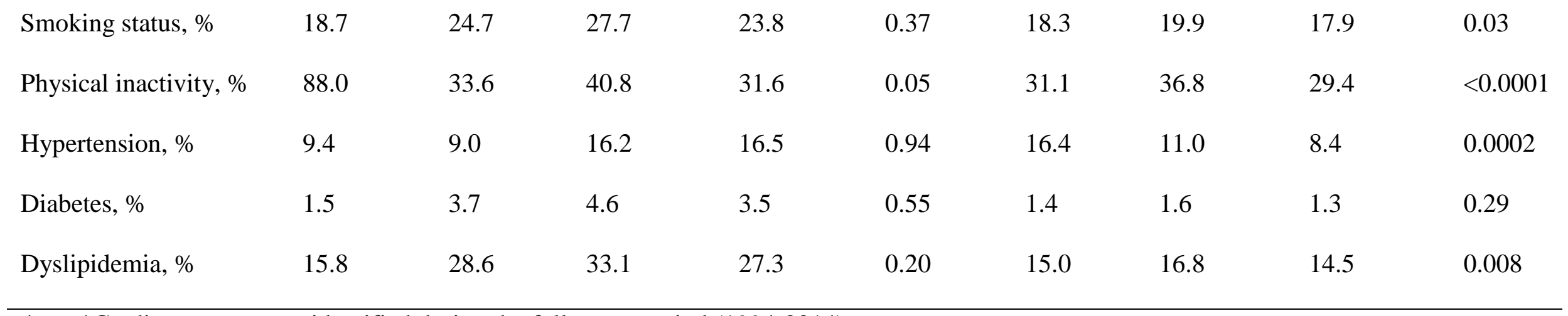

4. *Cardiac events were identified during the follow-up period (1994-2014)

5. $\quad{ }^{\dagger}$ Depression was defined as having a CES-D score $\geq 17 / 23$ for men/women

6. SD: standard deviation; CES-D: Center Epidemiologic Studies Depression Scale; CHD: coronary heart disease

7. Chi-square (or Fisher's exact test when necessary) and ANOVA tests were computed for discrete and continuous variables respectively. 
Table 2. Depression and cardiovascular risk factors in relation to incident cardiac events in the Gazel cohort, 1994-2014 (hazard ratios (HR), 95\% confidence intervals (CI), p-value for interaction)

\begin{tabular}{|c|c|c|c|c|c|c|c|}
\hline & \multicolumn{4}{|c|}{ Minimally-adjusted model* } & \multicolumn{3}{|c|}{ Fully-adjusted model $^{\dagger}$} \\
\hline & $\begin{array}{l}\text { Total } \\
\text { cases }\end{array}$ & $\mathrm{HR}(95 \% \mathrm{CI})$ & $P$ & $P$-interaction & HR (95\% CI) & $P$ & $P$-interaction \\
\hline \multicolumn{8}{|c|}{ Depression $\infty$} \\
\hline No & 462 & 1.00 & Ref & $\ldots$ & 1.00 & Ref & $\cdots$ \\
\hline Yes & 130 & $1.72(1.37-2.17)$ & $<0.0001$ & & $1.55(1.17-2.05)$ & 0.002 & \\
\hline \multicolumn{8}{|c|}{ Hypertension } \\
\hline No & 495 & 1.00 & Ref & 0.32 & 1.00 & Ref & 0.79 \\
\hline Yes & 97 & $1.71(1.37-2.22)$ & $<0.0001$ & & $1.49(1.06-2.10)$ & 0.02 & \\
\hline \multicolumn{8}{|c|}{ Diabetes } \\
\hline No & 570 & 1.00 & Ref & 0.16 & 1.00 & Ref & 0.16 \\
\hline Yes & 22 & $2.88(1.87-4.44)$ & $<0.0001$ & & $2.54(1.46-4.42)$ & 0.001 & \\
\hline \multicolumn{8}{|c|}{ Dyslipidemia } \\
\hline No & 423 & 1.00 & Ref & 0.42 & 1.00 & Ref & 0.87 \\
\hline
\end{tabular}


$\infty$ Depression was defined as having a CES-D score $\geq 17 / 23$ for men/women

* Adjusted for sex, age in years and depression

${ }^{\dagger}$ Adjusted for sex, age in years, depression, hypertension, diabetes, dyslipidemia, occupational grade, parental CHD history, obesity, smoking status and physical inactivity

${ }^{\S} \mathrm{P}$-value for interaction of depression with each cardiovascular risk factor of interest 
Table 3. Risk of incident cardiac events associated with depressive symptoms (CES-D score) and cardiovascular risk factors in the Gazel cohort, 1994-2014 (hazard ratios (HR), 95\% confidence intervals (CI), p-value for interaction)

\begin{tabular}{|c|c|c|c|c|c|c|c|}
\hline & \multicolumn{4}{|c|}{ Minimally-adjusted model* } & \multicolumn{3}{|c|}{ Fully-adjusted model $^{\dagger}$} \\
\hline CES-D score $* *$ & 592 & $1.31(1.16-1.48)$ & $<0.0001$ & $\ldots$ & $1.29(1.12-1.49)$ & 0.0003 & $\ldots$ \\
\hline No & 495 & 1.00 & Ref & & 1.00 & Ref & \\
\hline Yes & 97 & $1.78(1.36-2.33)$ & $<0.0001$ & & $1.49(1.06-2.09)$ & 0.02 & \\
\hline Diabetes & & & & 0.50 & & & 0.31 \\
\hline No & 423 & 1.00 & Ref & & 1.00 & Ref & \\
\hline Yes & 169 & $1.73(1.36-2.20)$ & $<0.0001$ & & $1.53(1.15-2.05)$ & 0.004 & \\
\hline
\end{tabular}

* Adjusted for sex, age in years and depression 
${ }^{\dagger}$ Adjusted for sex, age in years, depression, hypertension, diabetes, dyslipidemia, occupational grade, parental CHD history, obesity, smoking status and physical inactivity

${ }^{\S} \mathrm{P}$-value for interaction of CES-D score with each cardiovascular risk factor of interest

** HR values were given for one interquartile range of CESD-score as 10 units 
Table 4. Risk of incident cardiac events associated with depressive symptoms (CES-D score) in subpopulations according to cardiovascular risk factors of interest in the Gazel cohort, 1994-2014 (hazard ratios (HR), 95\% confidence intervals (CI), p-value for interaction)

\begin{tabular}{|c|c|c|c|c|c|}
\hline & & Minimally-adjusted* & & Fully-adjusted model $^{\dagger}$ & \\
\hline & Total cases & $\mathrm{HR}(95 \% \mathrm{CI})^{\S}$ & $P$ & $\mathrm{HR}^{\dagger}(95 \% \mathrm{CI})^{\S}$ & $P$ \\
\hline \multicolumn{6}{|l|}{ Hypertension } \\
\hline Never & 241 & $1.31(1.09-1.58)$ & 0.004 & $1.32(1.07-1.63)$ & 0.009 \\
\hline At least once & 351 & $1.28(1.08-1.50)$ & 0.004 & $1.26(1.05-1.52)$ & 0.02 \\
\hline \multicolumn{6}{|l|}{ Diabetes } \\
\hline Never & 459 & $1.23(1.07-1.42)$ & 0.004 & $1.23(1.05-1.45)$ & 0.01 \\
\hline At least once & 133 & $1.42(1.13-1.79)$ & 0.003 & $1.46(1.12-1.91)$ & 0.006 \\
\hline \multicolumn{6}{|l|}{ Dyslipidemia } \\
\hline Never & 141 & $1.14(0.90-1.46)$ & 0.28 & $1.27(0.98-1.64)$ & 0.07 \\
\hline At least once & 451 & $1.34(1.16-1.54)$ & $<0.0001$ & $1.29(1.09-1.53)$ & 0.003 \\
\hline \multicolumn{6}{|c|}{$\mathbf{N}$ cardiovascular risk factors } \\
\hline None & 62 & $1.16(0.84-1.61)$ & 0.36 & $1.34(0.94-1.89)$ & 0.10 \\
\hline 1 & 216 & $1.19(0.95-1.49)$ & 0.12 & $1.20(0.94-1.53)$ & 0.15 \\
\hline
\end{tabular}


* Adjusted for sex, age in years and depression

$\dagger$ Adjusted for sex, age in years, depression, hypertension, diabetes, dyslipidemia, occupational grade, parental CHD history, obesity, smoking status and physical inactivity

${ }^{\S}$ HR values of incident cardiac events by depressive symptoms were given for one interquartile range of CESD-score as 10 units 